\title{
Análisis histórico genético de la población de la región de Antofagasta revela discontinuidad en la costa y valles interiores
}

\section{A genetic-historical analysis of the Antofagasta Region population shows discontinuity between the coast and the interior valleys}

Michelle de Saint Pierre ${ }^{1}$ https://orcid.org/0000-0001-6516-5314

Macarena Faure Echeverría ${ }^{2}$ https://orcid.org/0000-0001-7054-2364

Héctor Morales ${ }^{3}$ https://orcid.org/0000-0002-1156-0826

${ }^{1}$ Laboratorio de Genética, Departamento de Antropología, Universidad de Chile, CHILE. Email: michelle.desan@gmail.com

${ }^{2}$ Laboratorio de Genética, Departamento de Antropología, Universidad de Chile, Ignacio Carrera Pinto 1045, Nuńoa, Santiago, CHILE. Email: macarena.faure.echeverria@gmail.com

${ }^{3}$ Laboratorio de Etnografía, Departamento de Antropología, Universidad de Chile, Ignacio

Carrera Pinto 1045, Nuñoa, Santiago, CHILE. Email: hmorales@u.uchile.cl

\begin{abstract}
Resumen
Los estudios genéticos de marcadores de herencia uniparental como el ADN mitocondrial han sido usados con éxito por años para estudiar el poblamiento, historia y orígenes de poblaciones humanas. En la población chilena, la mayoría de estos estudios publicados ha sido realizada con poblaciones del sur de país, existiendo un vacío respecto al norte de Chile. Con el objetivo de profundizar en las dinámicas propias de la costa y valles interiores de la región de Antofagasta, analizamos, a nivel de frecuencias de haplogrupos mitocondriales, 207 individuos de las ciudades de Antofagasta y Calama (región de Antofagasta). Los resultados muestran una importante diferencia entre la costa y los valles; a pesar de la cercanía geográfica, ambos lugares se presentan como unidades poblacionales diferentes. La explicación podemos encontrarla en los patrones sociales y culturales propios de las poblaciones de la región, las cuales gracias a sus redes de parentalidad fueron desarrollando diferentes modos de vida, el costero y puneńo, dejando una huella biológica que perdura hasta hoy.
\end{abstract}

Palabras claves: movilidad, ADN mitocondrial, Andes, Calama.

\begin{abstract}
Studies of genetic markers of uniparental inheritance, such as mitochondrial DNA have been used successfully to study the settlement, history and origins of human populations. In the Chilean population, most published articles on the subject have been carried out with populations from southern Chile, leaving a gap on our knowledge about northern populations. In order to delve into population dynamics of the coast and interior valleys of the Antofagasta region, we analyzed 207 individuals from the cities of Antofagasta and Calama, to determine the frequency of mitochondrial haplogroups in each one. The results show a significant difference between the coast and the valleys; despite their geographical proximity, the genetic differences between them suggest they can be considered different population units. These differences probably result from the social and cultural patterns of these populations in the past, which, due to their kinship networks, were developing different ways of life over time: the coast and the puna lifestyles, leaving a biological imprint that lasts to this day.
\end{abstract}

Keywords: mobility, mitochondrial DNA, Andes, Calama.

Recibido: 30 abril 2019. Aceptado: 2 diciembre 2019 


\section{Introducción}

La región de Antofagasta se ubica en pleno desierto de Atacama, limitando al este con la Provincia de Jujuy en Argentina y el Departamento de Potosí en Bolivia, al oeste con el océano Pacífico, al norte con la región de Tarapacá -con fuerte presencia de población aymara- y al sur con la región de Copiapó donde existen formalmente comunidades collas. Administrativamente la región está dividida en tres provincias -Antofagasta, Tocopilla y El Loa- y nueve comunas. La provincia de Antofagasta está conformada por las comunas de Antofagasta, Mejillones, Sierra Gorda y Taltal; la provincia de Tocopilla por las de Tocopilla y María Elena y la provincia de El Loa por Ollagüe, Calama y San Pedro de Atacama (SPA), esta última un Área de Desarrollo Indígena (ADI) (Figura 1).

La etnogénesis jurídica atacameña iniciada por la Ley Indígena en el año 1993 (Ley 19.253) tiene un fundamento en el modo de vida de los pobladores de Atacama, como también en aspectos fenotípicos de la población indígena (Morales, 2013). Según el Censo 2002, la etnia atacameña es el principal pueblo indígena de la región de Antofagasta, representando el 59,7\% (13.874 personas) del total de la población indígena en la región (23.230 personas), seguida por los mapuche con $18,9 \%$, aymara con
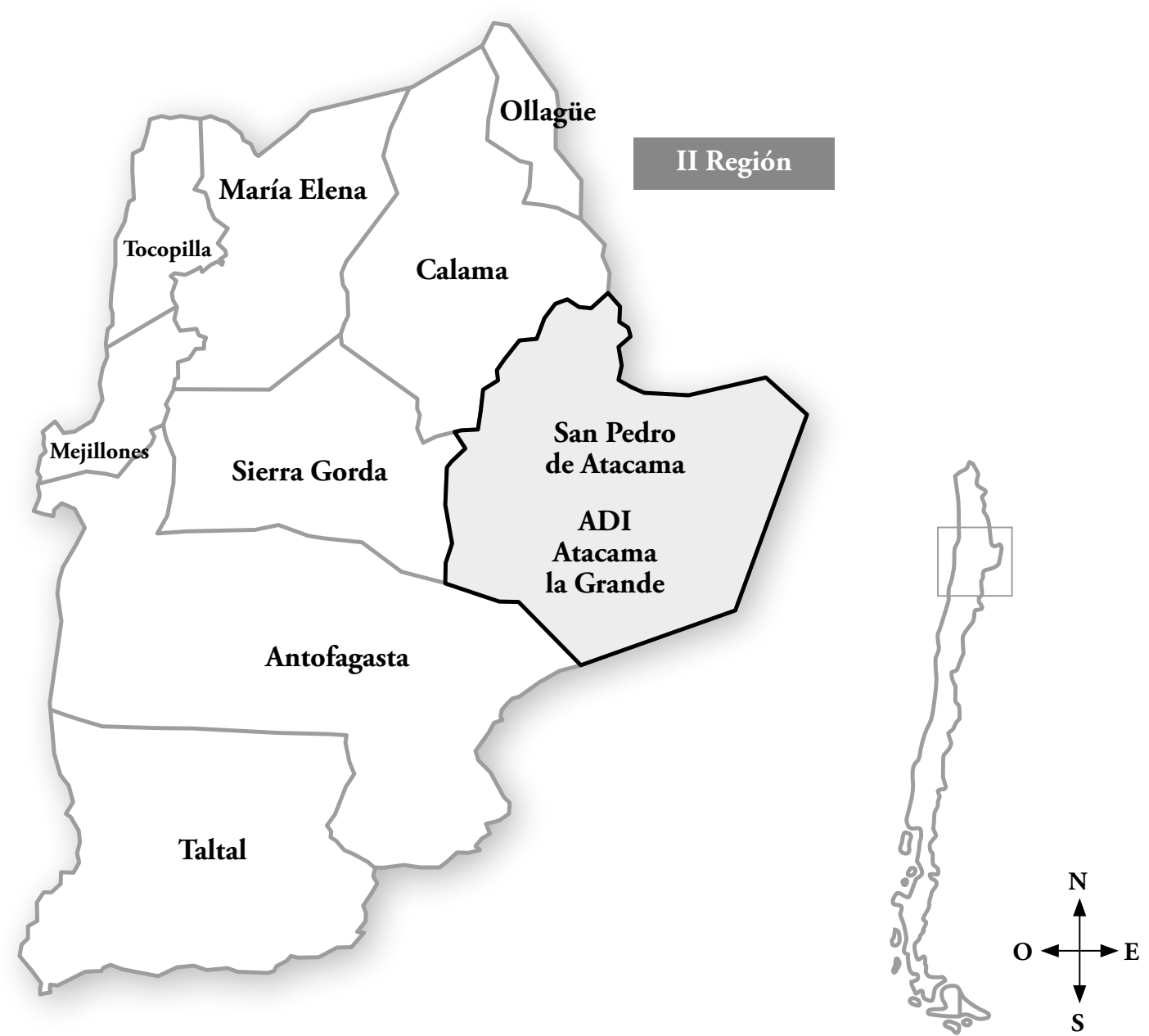

Figura 1. Mapa de la región de Antofagasta, separada de acuerdo a sus comunas. Fuente: Conadi. 
un 11\% y quechua con un 8,9\% (Mideplan, 2004). En el reciente XVII Censo Nacional de Población y VI de Vivienda realizado en el año 2017, se señala que la población atacameña alcanzó 30.369 personas, de las cuales una cantidad considerable, después de un largo proceso de integración, reside en la ciudad de Calama.

Si bien en la actualidad el pueblo atacameño (o lican antay) es la única población indígena reconocida como originaria en la región de Antofagasta, los antecedentes arqueológicos dan cuenta desde tiempos prehispánicos de un universo muy diferente al actual; la evidencia muestra la existencia de varios grupos diferenciados económica, política y lingüísticamente, lo que ha sido reafirmado por los estudios etnohistóricos de la zona. La población de la puna de Atacama, pastores de camélidos con actividades agrícolas, se caracterizaba por tener actividades económicas regidas por una alta movilidad dentro de un espacio macrorregional, lo cual incluye entre otros, contactos con Tiwanaku del lago Titicaca y con Aguada en el Noroeste Argentino, así como una gran movilidad a través de diferentes elevaciones, pudiendo aprovechar recursos en los diferentes pisos ecológicos (Sanhueza, 1992; Castro, Berenguer, Gallardo, Llagostera y Salazar 2016; Santoro et al., 2016). Esta movilidad pudo ser sustentada gracias a los camélidos domesticados, especialmente llamas, con los cuales podían formar grandes caravanas y recorrer miles de kilómetros para comerciar e intercambiar productos (Knudson, Pestle, Torres-Rouff y Pimentel 2010).

En la costa se encontraban grupos de pescadores o cazadores-recolectores marinos, los cuales han sido mencionados en documentos coloniales de diferentes maneras (camanchacas, urus, proanches y/o changos) (Ballester y Gallardo, 2017). Estos grupos han sido reconocidos por su alta movilidad latitudinal así como también por el aprovechamiento integral del lobo marino en la construcción de balsas, viviendas, vestuario, alimento, recipientes y cordelería (Phillippi, 1860). Knudson et al. (2010) reconocen para estas poblaciones un tipo de movilidad a pequeña escala, en la cual los individuos viajaban desde la costa al interior con el objetivo de obtener materias primas y recursos que no se encontraban en la costa, como piedras para líticos o ciertas plantas como el algarrobo (Prosopis spp.). Estas poblaciones tuvieron una impor- tante presencia en la costa hasta antes de la Colonia. Sin embargo, sus números declinaron rápidamente a medida que avanzaba el proceso de colonización; a mediados del siglo XIX se consignaba una población pequeña pero estable en la localidad de Cobija (hoy una caleta pesquera, ubicada entre Tocopilla y Antofagasta), sin embargo entrado el siglo XX son considerados extintos (Latcham, 1910; Castro, 2001).

A nivel genético la región de Antofagasta cuenta con pocos estudios, generándose un vacío de información respecto a otros grupos chilenos. El estudio de De Saint Pierre et al. (2012), a través del análisis de la región hipervariable del $\mathrm{ADN}$ mitocondrial (AD$\mathrm{Nmt}$ ), incluyó una muestra con 28 individuos atacameńos, dentro de una muestra mayor de población indígena mapuche, pehuenche, huilliche y aymara. A pesar de que en dicho trabajo el enfoque estuvo dado en la descripción de dinámicas poblacionales de las comunidades del sur, incluyendo el análisis de tres subhaplogrupos de ADNmt (D1g, B2i2 y C1b13) propios del sur de Chile y Argentina, se obtuvieron algunos datos interesantes; se pudo confirmar el patrón de gradiente latitudinal de los haplogrupos mitocondriales, en especial la alta proporción del grupo $\mathrm{B} 2$ en poblaciones andinas $(64,1 \%$ en aymara; $57,1 \%$ en atacameńo), el cual disminuye a medida que se avanza hacia el sur (en mapuche, huilliche y pehuenche las frecuencias de B2 oscilan entre el 15\% y el $40 \%)$. Además, se encontró el sublinaje andino B2aj (recientemente descrito sobre la base del genoma mitocondrial completo por Gómez-Carballa et al., 2018) en aymara y atacameño en porcentajes bastantes altos $(28,2 \%$ y $10,7 \%$ respectivamente), soportando la relación de las poblaciones del norte con otras poblaciones andinas. Otro linaje aún no descrito, identificado sobre la base de las mutaciones de la región hipervariable en el sitio 215 y la inserción de $\mathrm{T}$ en el sitio 455 (B2-455+T de aquí en adelante), fue encontrado en proporciones del $21,4 \%$ en atacameños y $15,3 \%$ en aymara. Dicho linaje fue encontrado también en tres de cinco individuos analizados del cementerio Pica 8 pertenecientes al complejo Pica-Tarapacá (Llamas et al., 2016).

Otros estudios con ADNmt han sido realizados con poblaciones mestizas y se han centrado en localidades rurales como los valles de Azapa, Camarones y Caleta Paposo por el norte; el valle de Aconcagua, 
por la zona central; y Carelmapu, Quetalmahue, Detif y Chiloé por la región del sur (Moraga, Pezo y De Saint Pierre et al., 2016). A su vez, la población chilena urbana ha sido caracterizada por las ciudades de Iquique, San Felipe, Los Andes, Santiago, Concepción, Temuco y Punta Arenas (Gómez-Carballa et al., 2016). De la totalidad de poblaciones estudiadas, es preciso resaltar que el patrón de gradiente latitudinal observado en poblaciones originarias se mantiene en la población mestiza. Por ejemplo, en los valles de Azapa y Camarones la frecuencia del haplogrupo B2 alcanza un 53\% y 70\%, respectivamente, en Caleta Paposo un 48\%, mientras que en el valle de Aconcagua alcanza valores de un $41 \%$. Más al sur, en Chiloé, este linaje no supera el 30\% (Moraga et al., 2016). Respecto a los linajes andinos mencionados anteriormente, la presencia es baja, detectándose un $2,7 \%$ en Iquique y $1,6 \%$ en Santiago para B2aj. B2-455+T no se encuentra presente en las poblaciones mencionadas.

A pesar del esfuerzo realizado por numerosos investigadores, el conocimiento existente acerca del origen de la mayoría de los pueblos originarios chilenos continúa siendo fragmentario y parcialmente contradictorio. En consecuencia nos hemos propuesto contribuir al esclarecimiento de este importante aspecto de los grupos cordilleranos de la segunda región, ofreciendo un enfoque desde la perspectiva de la genética histórica. Este trabajo tiene como objetivo principal analizar la población de la región de Antofagasta y la relación existente entre poblaciones de la costa y valles altos, a través del análisis de las frecuencias de linajes de haplogrupos y subhaplogrupos de ADN mitocondrial. Para esto se obtuvo muestra de $A D N$ de 207 individuos, los cuales fueron agrupados según el lugar de nacimiento de la abuela materna/madre en los siguientes grupos: Costa norte, Salitreras, Calama y Chuquicamata y Pueblos del interior.

\section{Metodología}

\section{Muestra}

Se obtuvo un total de 207 muestras de saliva provenientes de individuos adultos que fueron reclutados en las ciudades de Antofagasta y Calama. Los y las participantes del estudio contestaron un breve cuestionario sobre el lugar de origen de padres y abuelos, y se solicitó además $2 \mathrm{ml}$ de saliva, la cual fue mezclada con tampón de mantención. Cada participante firmó un consentimiento informado aprobado por el comité de ética de la investigación, de la Facultad de Ciencias Sociales de la Universidad de Chile.

\section{Extracción y secuenciación del ADN}

Se utilizó el protocolo modificado de Quinque, Kittler, Kayser, Stoneking y Nasidze et al. (2006). Para esto se mezcló $1 \mathrm{ml}$ de saliva con un tampón de lisis, al cual se agregó proteinasa $\mathrm{K}$, incubándose las muestras a $53^{\circ} \mathrm{C}$ toda la noche, de tal forma de romper la matriz celular y posibilitar la liberación del ADN. Posteriormente se agregó $\mathrm{NaCl}$, seguido de centrifugación a $13.000 \mathrm{rpm}$ por 15 minutos. El sobrenadante fue recuperado y el ADN se precipitó con isopropanol frío. El precipitado fue lavado con etanol $75 \%$ y finalmente resuspendido en agua de grado molecular. Posteriormente, la región hipervariable del ADN mitocondrial fue amplificada por PCR siguiendo las condiciones especificadas en Moraga et al. (2000). Los fragmentos amplificados fueron enviados a secuenciar a Macrogen, Corea del Sur. La detección de los polimorfismos en las secuencias fue realizada al ojo mediante el programa Sequencher 5.4.5.

\section{Determinación de haplogrupos mitocondriales.}

A través de los polimorfismos presentes en la secuencia de la región hipervariable entre los sitios 16024-16550 y 40-550 (datos no mostrados), se determinó la pertenencia a un haplogrupo determinado usando la base de dato MITOMASTER (Lott et al., 2013), y verificados los linajes resultantes en el sitio web de Phylotree (Van Oven y Kayser, 2009).

\section{Análisis de datos}

Los 207 individuos analizados fueron agrupados en cuatro submuestras según el lugar de nacimiento de su abuela materna, y en caso de no contar con el dato, de la madre. El objetivo de este agrupamiento fue disminuir el sesgo producido por migraciones recientes, en el cual individuos provenientes de otras 
regiones pasan a formar parte del lugar muestreado. Los grupos fueron Costa norte ( $\mathrm{n}=87$, Antofagasta, Tocopilla y Mejillones), Oficinas Salitreras ( $n=24)$, Calama-Chuquicamata $(\mathrm{n}=63)$ y Pueblos del interior $(\mathrm{n}=32$, Pueblo Hundido, San Pedro de Atacama, Río Grande, Ayquina, Sana, Toconce, Caspana, Lasana, Socaire, Toconao, Ollagüe). Se realizó además un análisis de distancias genéticas con el programa Arlequin 3.5 (Excoffier y Lischer, 2010), y con la matriz de distancias entre pares (pairwise) resultante se construyó un dendrograma Neighbor Joining (NJ) con el software MEGA 7 (Kumar, Stecher y Tamura et al., 2016). Para los análisis se agregaron los datos de frecuencias de linajes mitocondriales obtenidos en el estudio de De Saint Pierre et al. (2012) para aymara $(n=39)$, atacameño $(n=28)$, mapuche $(n=19)$, pehuenche $(n=42)$ y huilliche $(n=61)$, y los obtenidos por Gómez-Carballa et al. (2016) para una muestra de 995 individuos de diferentes lugares de Chile. Los datos fueron reanalizados tomando en cuenta el lugar de nacimiento del individuo en vez del lugar de muestreo, generando información para las siguientes localidades; Iquique $(\mathrm{n}=73)$, Valparaíso/Viña del Mar $(\mathrm{n}=26)$, Santiago $(\mathrm{n}=188)$, Concepción $(n=112)$ y Temuco $(n=90)$.

\section{Resultados}

\section{Frecuencias de haplogrupos mitocondriales}

A través del análisis de polimorfismos, se detectaron en porcentajes diferentes los siguientes haplogrupos y subhaplogrupos amerindios: A2, B2, B2ai, B2aj, B2y, B2-455+T, B2i2, C1, C1b8, C1b13, C1d1, D1, D1g, D1j y D4h3a (ver <www.phylotree.org> para una descripción detallada de ellos), en porcentajes que van entre $89,5 \%$ y $100 \%$ (Tabla 1). Respecto a los haplogrupos no americanos, agrupados en la categoría de NA (No Amerindio), se observaron linajes de origen europeo (HV0, U5, H) y africano

Tabla 1. Porcentajes de frecuencias de sublinajes mitocondriales por población. En gris, poblaciones de este estudio.

\begin{tabular}{|c|c|c|c|c|c|c|c|c|c|c|c|c|c|c|c|c|c|c|c|}
\hline $\begin{array}{l}\text { Grupos/ } \\
\mathrm{Hg}\end{array}$ & $\mathbf{n}$ & $\begin{array}{l}\% \\
\text { A2 }\end{array}$ & $\begin{array}{l}\% \\
\text { B2 }\end{array}$ & $\begin{array}{l}\% \\
\text { B2ai }\end{array}$ & $\begin{array}{l}\text { \% } \\
\text { B2aj }\end{array}$ & $\begin{array}{l}\% \\
\text { B2y }\end{array}$ & $\begin{array}{l}\% \\
\text { B2- } \\
455+T\end{array}$ & $\begin{array}{c}\% \\
\text { B2i2 }\end{array}$ & $\begin{array}{l}\% \\
\mathrm{C} 1\end{array}$ & $\begin{array}{l}\% \\
\text { C1b }\end{array}$ & $\begin{array}{l}\% \\
\text { C1b8 }\end{array}$ & $\begin{array}{l}\% \\
\text { C1b13 }\end{array}$ & $\begin{array}{l}\% \\
\text { C1d1 }\end{array}$ & $\begin{array}{l}\% \\
\text { D1 }\end{array}$ & $\begin{array}{l}\% \\
\text { D1g }\end{array}$ & $\begin{array}{l}\text { \% } \\
\text { D1j }\end{array}$ & $\begin{array}{l}\% \\
\text { D4h3a }\end{array}$ & $\begin{array}{l}\% \\
\text { NA }\end{array}$ & Ref. \\
\hline Aymara & 39 & 5,1 & 10,3 & 5,1 & 28,2 & 5,1 & 15,4 & 0 & 0 & 7,7 & 0 & 0 & 0 & 15,4 & 2,6 & 2,6 & 2,6 & 0 & 3 \\
\hline Iquique & 73 & 11 & 8,2 & 1,4 & 2,7 & 0 & 0 & 21,9 & 4,1 & 9,6 & 1,4 & 15,1 & 5,5 & 0 & 9,6 & 2,7 & 2,7 & 4,1 & 2 \\
\hline $\begin{array}{l}\text { Costa } \\
\text { norte }\end{array}$ & 87 & 10,3 & 12,6 & 0 & 0 & 0 & 1,1 & 17,2 & 4,6 & 8 & 1,1 & 8 & 0 & 5,7 & 12,8 & 3,8 & 6,4 & 9,3 & 1 \\
\hline $\begin{array}{l}\text { Oficinas } \\
\text { salitreras }\end{array}$ & 24 & 12,5 & 20,8 & 4,2 & 0 & 4,2 & 0 & 4,2 & 0 & 4,2 & 0 & 4,2 & 12,5 & 0 & 11,5 & 3,4 & 5,7 & 10,5 & 1 \\
\hline $\begin{array}{l}\text { Calama- } \\
\text { Chuquica- } \\
\text { mata }\end{array}$ & 63 & 12,7 & 12,7 & 1,6 & 9,5 & 4,8 & 3,2 & 17,5 & 1,6 & 7,9 & 0 & 6,3 & 1,6 & 4,8 & 7,9 & 3,2 & 0 & 4,6 & 1 \\
\hline Atacameńo & 28 & 25 & 25 & 0 & 10,7 & 0 & 21,4 & 0 & 0 & 7,1 & 0 & 3,6 & 0 & 3,6 & 0 & 3,6 & 0 & 0 & 3 \\
\hline $\begin{array}{l}\text { Pueblos } \\
\text { del } \\
\text { interior }\end{array}$ & 32 & 6,3 & 21,9 & 0 & 25 & 0 & 25 & 0 & 3,1 & 6,3 & 0 & 0 & 3,1 & 6,3 & 0 & 3,1 & 0 & 0 & 1 \\
\hline $\begin{array}{l}\text { Valparaí- } \\
\text { so/Viña de } \\
\text { mar }\end{array}$ & 26 & 7,7 & 19,2 & 0 & 0 & 0 & 0 & 11,5 & 0 & 3,8 & 0 & 3,8 & 7,7 & 0 & 19,2 & 0 & 7,7 & 19,2 & 2 \\
\hline Santiago & 188 & 6,9 & 6,4 & 0 & 1,6 & 0 & 0 & 17,6 & 1,1 & 7,4 & 0,5 & 19,1 & 1,1 & 3,7 & 18,1 & 0 & 3,2 & 13,3 & 2 \\
\hline $\begin{array}{l}\text { Concep- } \\
\text { ción }\end{array}$ & 112 & 5,4 & 7,1 & 0 & 0 & 0 & 0 & 17,9 & 0 & 3,6 & 0,9 & 19,6 & 1,8 & 2,7 & 24,1 & 0 & 0,9 & 16,1 & 2 \\
\hline Temuco & 90 & 7,8 & 2,2 & 0 & 0 & 0 & 0 & 23,3 & 2,2 & 4,4 & 0 & 28,9 & 0 & 4,4 & 16,7 & 0 & 2,2 & 7,8 & 2 \\
\hline Mapuche & 19 & 0 & 10,5 & 0 & 0 & 0 & 0 & 26,3 & 0 & 15,8 & 0 & 26,3 & 0 & 0 & 15,8 & 0 & 5,3 & 0 & 3 \\
\hline Pehuenche & 42 & 7,1 & 0 & 0 & 0 & 0 & 0 & 26,2 & 0 & 0 & 0 & 28,6 & 0 & 0 & 38,1 & 0 & 0 & 0 & 3 \\
\hline Huilliche & 61 & 9,8 & 0 & 0 & 0 & 0 & 0 & 24,6 & 1,6 & 3,3 & 0 & 13,1 & 0 & 3,3 & 36,1 & 0 & 3,3 & 4,9 & 3 \\
\hline
\end{tabular}

Referencias: ${ }^{1}$ Este estudio, ${ }^{2}$ Gómez-Carballa et al., 2016, ${ }^{3}$ De Saint Pierre et al., 2012. 
(L2 y L3). Tanto para linajes americanos como NA, los porcentajes se encuentran dentro del rango detectado para otras poblaciones chilenas.

Al observar las frecuencias en población urbana del norte en Costa norte (que incluye Antofagasta, Tocopilla y Mejillones), así como Iquique (GómezCarballa et al., 2016), llama la atención los altos porcentajes de los subhaplogrupos propios del centro-sur de Chile B2i2 ( $20,6 \%)$, D1g $(-11,2 \%)$ y C1b13 $(-12 \%)$, los cuales están ausentes en la población nativa del norte de Chile (a excepción de un D1g en aymara y un C1b13 en atacameño; De Saint Pierre et al., 2012). Estos datos probablemente reflejan la intensa migración proveniente del sur en el siglo XX, sobre todo con respecto a $\mathrm{B} 2 \mathrm{i} 2$, linaje característico de poblaciones indígenas del sur (De Saint Pierre et al., 2012, reportan para mapuche, pehuenche y huilliche las frecuencias de B2i2 - 25,7\%, D1g - 30\%, y C1b13 -22,7\%). Por otra parte, en las poblaciones costeras están prácticamente ausentes los linajes "nortinos" B2aj y B2-455+T encontrados en aymara y atacameño, a excepción de dos individuos B2aj en Iquique y un individuo B2-455+T en Costa norte, Antofagasta. Al comparar los dos grupos de los valles altos analizados, Calama-Chuquicamata y Pueblos del interior, se advierte una situación intermedia en Calama y Chuquicamata, con presencia de los linajes del sur $(\mathrm{B} 2 \mathrm{i} 2=16,9 \% ; \mathrm{D} 1 \mathrm{~g}=7,7 \%$ y C1b13 $=6,2 \%)$ y del norte B2aj $(9,2 \%)$ y B2-455+T (3,1\%). En Pueblos del interior, por otra parte, los linajes del sur están ausentes mientras que los linajes del norte B2aj y B2-455+T se encuentran en frecuencias altas (25\% cada uno).

Respecto a los linajes foráneos, las poblaciones analizadas muestran frecuencias dentro de los porcentajes reportados para otras poblaciones urbanas chilenas: Costa norte $=9,3 \%$, Salitreras $=8,3 \%$ y Calama-Chuquicamata $=6,2 \%$ (valores para otras ciudades: $4,1 \%$ en Iquique; $19,2 \%$ en ValparaísoViña del Mar; 13,1\% en Santiago; ver Tabla 1). Solo en el subgrupo Pueblos del interior no se encontró ningún haplogrupo no amerindio, similar a lo encontrado en poblaciones indígenas de Chile (De Saint Pierre et al., 2012). Respecto al origen de los linajes no amerindios, llaman la atención los porcentajes de linajes de origen africano encontrados en la región de Antofagasta, los cuales triplican los valores encontrados en otras zonas; Costa norte 5,7\% (L2a, L2b, L2d, L3e1 y L3d2), Calama-Chuquicamata 3,2\% (L3e1 y L3e3) y Salitreras 4,5\% (L3), mientras que en otras ciudades en que se encuentran linajes africanos los valores son entre 1 y $2 \%$; Iquique (L3b2 $=1,4 \%)$, Concepción $(\mathrm{L} 2 \mathrm{a} 1=1 \%)$ y Santiago (L1c1, L3e2 y L1b1 = 1,6\%).

\section{Distancias genéticas Fst y dendrograma NJ}

Se realizó un análisis de distancias genéticas (matriz de Fst, Tabla 2) con el software Arlequin 3.5 y se construyó un dendrograma Neighbor Joining sobre la base de la matriz de distancias obtenida (Figura 2). En el dendrograma se aprecia claramente que las poblaciones analizadas se dividen en dos grupos, uno conformado por aymara, atacameños y Pueblos del interior, y el segundo conformado por el resto de las poblaciones analizadas, incluyendo centros urbanos del norte (Costa norte, Iquique y Calama-Chuquicamata), centro (Valparaíso/Viña del Mar y Santiago) y sur de Chile (Concepción y Temuco), junto con las poblaciones nativas del sur de Chile mapuche, pehuenche y huilliche. Esta diferencia puede estar explicada en parte por el porcentaje de haplogrupos del sur, lo que hace que ciudades como Iquique y Antofagasta (representada en Costa norte) se encuentren más cercanas a Santiago (Fst Iquique/Santiago 0,008; Antofagasta/Santiago 0,006 , respectivamente), a pesar de la distancia geográfica de mil km, que con población de los valles altos, como atacameńo (Fst Atacameńo/Iquique 0,072; atacameńo/Costa norte 0,058) o Pueblos del interior (Fst Pueblos/Iquique 0,093; Pueblos/ Costa norte 0,082). Calama representa una situación intermedia, con una mayor diferenciación con Santiago (Fst Calama/Santiago 0,019) respecto a las ciudades costeras del norte y una menor respecto a atacameño (Fst Calama/Atacameño 0,032) y Pueblos del interior (Fst Calama/pueblos 0,046). Es interesante que, a pesar de la cercanía geográfica con atacameños y Pueblos del interior, a nivel genético Calama se muestra más cercana a Santiago, lo que demuestra el impacto que las migraciones del centro-sur han tenido en las zonas urbanas de la zona norte. 
Tabla 2. Matriz de distancias genéticas. Bajo la diagonal, los valores de Fst, y sobre la diagonal, los valores de significancia estadística. En negrita, valores con significancia estadística $\mathrm{p}<0,05$.

\begin{tabular}{|c|c|c|c|c|c|c|c|c|c|c|c|c|c|c|}
\hline & 1 & 2 & 3 & 4 & 5 & 6 & 7 & 8 & 9 & 10 & 11 & 12 & 13 & 14 \\
\hline $\begin{array}{l}\text { 1. Oficinas } \\
\text { salitreras }\end{array}$ & & 0,003 & 0,306 & 0,207 & $<0,001$ & 0,046 & 0,022 & $<0,001$ & 0,002 & 0,075 & 0,897 & 0,020 & 0,016 & 0,001 \\
\hline $\begin{array}{r}\text { 2. Pueblos } \\
\text { interior }\end{array}$ & 0,065 & & 0,001 & $<0,001$ & 0,538 & 0,346 & $<0,001$ & $<0,001$ & $<0,001$ & $<0,001$ & $<0,001$ & $<0,001$ & $<0,001$ & $<0,001$ \\
\hline $\begin{array}{l}\text { 3. Calama-Chu- } \\
\text { quicamata }\end{array}$ & 0,004 & 0,046 & & 0,557 & 0,001 & 0,018 & 0,071 & $<0,001$ & $<0,001$ & 0,400 & 0,208 & 0,004 & 0,001 & $<0,001$ \\
\hline 4. Costa norte & 0,008 & 0,082 & 0,002 & & $<0,001$ & $<0,001$ & 0,238 & $<0,001$ & $<0,001$ & 0,509 & 0,436 & 0,048 & 0,003 & 0,001 \\
\hline 5. Aymara & 0,069 & 0,005 & 0,040 & 0,074 & & 0,035 & $<0,001$ & $<0,001$ & $<0,001$ & $<0,001$ & $<0,001$ & $<0,001$ & $<0,001$ & $<0,001$ \\
\hline 6. Atacameño & 0,036 & 0,003 & 0,032 & 0,058 & 0,036 & & $<0,001$ & $<0,001$ & $<0,001$ & $<0,001$ & 0,003 & $<0,001$ & $<0,001$ & $<0,001$ \\
\hline 7. Mapuche & 0,052 & 0,131 & 0,023 & 0,009 & 0,119 & 0,118 & & 0,170 & 0,107 & 0,631 & 0,078 & 0,465 & 0,262 & 0,648 \\
\hline 8. Pehuenche & 0,114 & 0,221 & 0,089 & 0,072 & 0,197 & 0,203 & 0,024 & & 0,376 & 0,002 & 0,001 & 0,003 & 0,034 & 0,073 \\
\hline 9. Huilliche & 0,073 & 0,179 & 0,055 & 0,038 & 0,153 & 0,160 & 0,027 & $<0,001$ & & 0,003 & 0,018 & 0,008 & 0,057 & 0,018 \\
\hline 10. Iquique & 0,018 & 0,093 & 0,001 & 0,001 & 0,086 & 0,072 & 0,007 & 0,054 & 0,035 & & 0,092 & 0,112 & 0,014 & 0,073 \\
\hline $\begin{array}{c}\text { 11.Valparaíso/ } \\
\text { Viña }\end{array}$ & 0,021 & 0,089 & 0,008 & $<0,001$ & 0,091 & 0,070 & 0,036 & 0,091 & 0,044 & 0,017 & & 0,155 & 0,197 & 0,004 \\
\hline 12. Santiago & 0,032 & 0,118 & 0,019 & 0,008 & 0,102 & 0,101 & 0,001 & 0,035 & 0,021 & 0,006 & 0,010 & & 0,779 & 0,209 \\
\hline 13. Concepción & 0,039 & 0,139 & 0,032 & 0,018 & 0,125 & 0,123 & 0,009 & 0,025 & 0,014 & 0,018 & 0,009 & 0,003 & & 0,129 \\
\hline 14. Temuco & 0,068 & 0,155 & 0,039 & 0,026 & 0,135 & 1,134 & 0,010 & 0,019 & 0,026 & 0,010 & 0,050 & 0,003 & 0,007 & \\
\hline
\end{tabular}

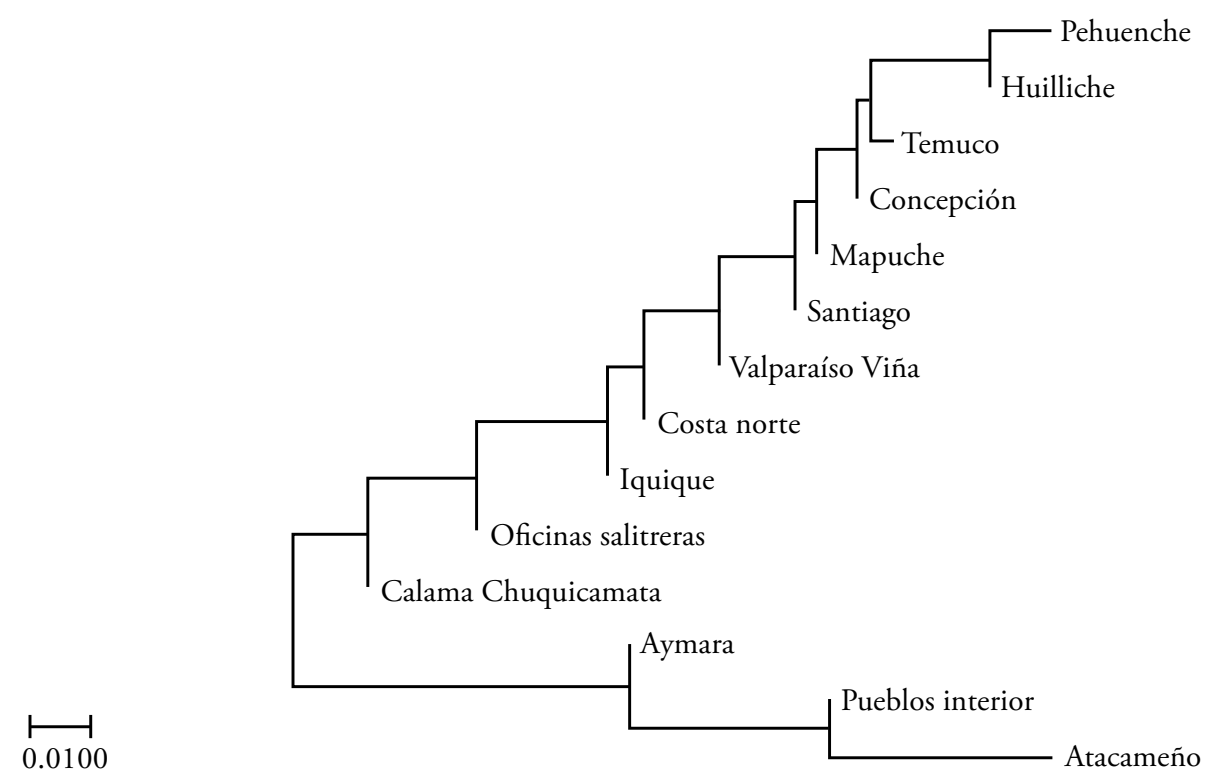

Figura 2. Dendrograma Neighbor Joining basado en las distancias genéticas de poblaciones urbanas y nativas de Chile. 


\section{Discusión}

Como hemos visto, la composición genética a nivel mitocondrial varía de forma importante entre las poblaciones costeras y aquellas de los valles interiores de la región de Antofagasta, a tal nivel que las poblaciones de la costa son más cercanas genéticamente a la población de Santiago, distante más de $1.500 \mathrm{~km}$, que a otras poblaciones altiplánicas. Estas diferencias, englobadas por la ausencia en el mundo andino de los linajes sureños D1g, B2i2 y C1b13 y la ausencia en la costa de linajes andinos B2aj y B2-455+T, nos lleva a preguntarnos acerca de qué proceso o procesos pueden dar cuenta de este fenómeno.

La casi total ausencia de los linajes andinos B2aj y B2-455+T en la costa estaría evidenciando que las redes de movilidad solo habrían tenido predominio en el aspecto económico (Murra, 1972 y 1975; Mayer y Alberti, 1974; Núñez y Dillehay, 1979; Santoro et al., 2016), no influenciando la composición biológica de las poblaciones tanto de la costa como de los valles. Interesantemente, Llamas et al. (2016), mediante un análisis de ADN antiguo, detectaron el linaje $\mathrm{B} 2-455+\mathrm{T}$ en tres individuos del cementerio Pica-8 (datación 1.000-1.476 AD), perteneciente al complejo Pica-Tarapacá. ${ }^{1}$ Este resultado nos da cuenta de una relación temporal profunda en el altiplano chileno, en tanto que en la actualidad dicho linaje sigue presente en las poblaciones, como en nuestra muestra de Pueblos del interior (25\%), así como en aymara de la primera región $(15,4 \%$, De Saint Pierre et al., 2012).

1 El complejo Pica-Tarapacá corresponde a una serie de asentamientos entre los valles de Camińa y el Loa, los cuales alcanzaron su apogeo durante el período Intermedio Tardío (ca. 900-1450 DC), y se ubicaban a una distancia de entre 300-200 km de SPA. Numerosa evidencia arqueológica da cuenta de la complejidad social y cultural de estas poblaciones, y a su vez altamente móviles en el espacio. Según Núñez y Briones, (2017), "la población Tarapaqueña, más que representar una difusa multietnicidad a raíz de sus conexiones de movilidad con la costa arreica, valles aledańos, sierra y altiplano aledaño, pareciera que había consolidado en los últimos siglos una sociedad monoétnica, derivada de comunidades formativas locales con ciertos componentes intrusivos multiétnicos".
La conexión genética revelada por la presencia de un linaje andino a lo largo de $500 \mathrm{~km}$ de altiplano chileno, y que abarca un espacio temporal de mil años aproximadamente, nos permite inferir respecto de las redes de parentesco de las poblaciones altiplánicas, y que las dinámicas encontradas en las poblaciones altiplánicas en la actualidad pueden tener un trasfondo temporal profundo y estar arraigadas desde hace miles de años.

Así como la evidencia arqueológica muestra la conexión costa-valles interiores en San Pedro de Atacama, lo hace también con las poblaciones del Complejo Pica-Tarapacá con la costa (Núñez y Briones, 2017). Al igual que ocurre con las ciudades costeras de Antofagasta, en Iquique no se ha encontrado el linaje $\mathrm{B} 2-455+\mathrm{T}$ (en una proporción de $\mathrm{B} 2$ total del $36 \%$ ). Sin embargo, hasta la fecha no hay datos de la población actual del altiplano iquiqueño, por lo que no es posible conocer si dichas poblaciones repiten el patrón encontrado en las comunidades de San Pedro de Atacama.

Respecto de las poblaciones cazadoras-pescadoras marinas del litoral del desierto de Atacama entre los siglos XVI-XIX, Ballester y Gallardo (2017) describen un sistema de parentesco y matrimonio similar al encontrado en las poblaciones de los valles interiores (Morales, 2018); en las poblaciones del litoral se establecían redes de parentesco con otras poblaciones costeras, nunca fuera de él. Si bien las poblaciones costeras eran seminómades, estos grupos delimitaban zonas de pesca específicas. Así, las relaciones de parentesco y de matrimonio se destinaron a vincular únicamente a comunidades asentadas en distintos puntos del litoral, justamente para brindar una solución política a posibles conflictos frente a la superposición de estas cotas de pesca-caza.

Respecto a los habitantes de localidades cordilleranas, estos son esencialmente pastores, por lo que los matrimonios bien pudieron funcionar como un mecanismo político de anulación de posibles conflictos entre comunidades frente a la superposición de las cotas y territorios de pastoreo, convirtiendo de esta forma a todos quienes vivían en torno en parientes que compartían un territorio y los recursos forrajeros e hídricos (Grebe e Hidalgo, 1988; Núñez, Cartajena, Carrasco, De Souza y Grosjean, 2006). 
En términos prácticos, según nuestros estudios de la puna atacameńa, cada familia posee sus pastos de campo reconocidos, sobre los cuales no ostentan títulos de propiedad, aunque sí aducen posesión desde tiempos inmemoriales. En sociedades como la andina, la familia es algo más que un pequeño grupo de personas ligadas por vínculos fraternos; su ligazón a un determinado grupo les brinda una serie de derechos y deberes respecto de su grupo parental como frente a otros grupos (Morales, 1997).

Desde la etnografía, un aspecto cultural particularmente relevante para la regulación del parentesco proviene de diversos relatos que hacen referencia a las personas de los Pueblos del interior. Una profesora de la escuela pública E-26 San Pedro de Atacama, de la localidad homónima, nos señala: "...su cultura es más fuerte, se casan entre ellos, nunca se casan con gente de afuera de sus pueblos" (com. pers., profesora atacameña, 2008). Eso se expresa en la recurrencia de los mismos apellidos paternos y maternos que se repiten sucesivamente en las nuevas descendencias y se entrecruzan. Los apellidos visibilizan, de esa forma, troncos familiares extensos o familias extendidas en cada localidad (Morales, 2018). Esto pone en evidencia una suerte de aislamiento de la población puneña, lo que tiene como consecuencia que la influencia genética de migrantes foráneos sea muy baja. Incluso la llegada de la minería y el desarrollo de un gran centro urbano, como la ciudad de Calama, no ha tenido un efecto importante en la composición genética en los Pueblos del interior, según nuestros datos. Fue evidente el aislamiento de estas comunidades parentales cordilleranas hasta la década del setenta, cuando el control de pastos y cerros era clave para el desarrollo de sus actividades pastoriles (Morales, 2018). Ello nos muestra mecanismos socioculturales que se reflejan en la ausencia de linajes del mundo andino B2aj y B2-455+T en la costa y revela que este aislamiento genético entre la costa y los valles del interior es más profundo de lo que pudiera creerse.

Otros datos interesantes provienen de las costumbres religiosas y fiestas como el carnaval, previas a la cuaresma católica. Esa fiesta de raíz colonial y pagana (Martínez, 2005) es una práctica común en los pueblos cordilleranos hasta el día de hoy, en que se entremezcla la música, el baile, la comida y el alcohol; una vieja leyenda dice que en noches de carnaval se "escapa el diablo" (Morales, 2018), quedando todos a merced de los excesos propios de la carne previo a la cuaresma y abstinencia religiosa. Estos pequeños pueblos de cincuenta o menos habitantes durante estas fiestas se llenan de invitados, parientes lejanos y vecinos, pero nunca se invita a personas foráneas, ya que se le considera una fiesta o celebración íntima y familiar. A través de estos relatos etnográficos es posible encontrar explicaciones a la particular conformación de linajes encontrados en la muestra Pueblos del interior. Desde un punto de vista económico, los centros urbanos mineros de Calama y Antofagasta atraen una tasa mayor de migrantes laborales desde otras regiones del país. En cambio los pueblos del interior, inmediatamente colindantes, localidades agrícolas, ganaderas y pastoriles de subsistencia con un modo tradicional, no son un foco de atracción para población migrante.

\section{Haplogrupos no americanos}

Dentro de los linajes no americanos encontrados nos llamó la atención el porcentaje de haplogrupos africanos presente en la región de Antofagasta, en especial en la costa, que con un 5,7\%, triplica los valores encontrados en otras ciudades, incluyendo otra urbe nortina, Iquique.

Respecto a datos para ADN mitocondrial de otras ciudades chilenas, se observan valores entre el $0 \mathrm{y}$ $2 \%$ para todas las poblaciones publicadas (GómezCarballa et al., 2016). Es importante notar que no hay datos publicados para la población de Arica, y la única población del norte analizada, aparte de nuestras muestras, corresponde a la población de Iquique (1,4\% de haplogrupos africanos). Sin embargo, este valor puede estar afectado por el hecho de que el promedio total de haplogrupos no amerindios es bajo (cercano al 4\%). Respecto al ADN nuclear, los valores que se muestran son más cercanos a los datos etnohistóricos. El trabajo de Fuentes et al. (2014) encontró el mayor porcentaje de ancestría africana en la región de Tarapacá (5,7\%), seguido de las regiones de Antofagasta (5\%), Santiago (4,5\%), Valparaíso (4,3\%) y Arica y Parinacota (4,1\%). El estudio con SNPs nucleares de Eyheramendy, Martínez, Manevy, Vial y Repetto et al. (2015) replica los resultados anteriores, siendo la población del 
norte la con mayor porcentaje de ancestría africana $(3,89 \%)$, seguida de la zona centro $(2,46 \%)$ y del sur de Chile, con valores menores al $2 \%$. Si bien los porcentajes de variantes de ADN nuclear de ancestría africana son bajos, hay que notar que los resultados mostrados corresponden a un promedio total de todos los participantes analizados, lo que puede enmascarar individuos con porcentajes de ancestría africana más alta. Los datos genéticos expuestos confirman que en el norte de Chile se concentra el mayor porcentaje de personas con ancestría africana, los que probablemente corresponden a descendientes de población esclava llegada en tiempos de la Colonia. Si bien en la actualidad la región de Antofagasta concentra un importante porcentaje de población afrodescendiente, este proceso es reciente, no teniendo tiempo aún de impactar las frecuencias de linajes de ADN mitocondrial en la población local (Echeverri, 2016). Sin embargo, la región de Antofagasta no ha sido mencionada ni en los registros coloniales ni en programas reivindicatorios respecto a la comunidad afrodescendiente, lo que hace necesarios otros estudios para resolver esta cuestión. ${ }^{2}$

2 Durante bastante tiempo se ha debatido sobre la importancia de los esclavos chilenos en la conformación de la población criolla. Si bien la evidencia etnohistórica, así como la conformación actual de la población, muestra que efectivamente la migración africana en Chile no tuvo el mismo impacto que en otros países sudamericanos, como Brasil, Colombia y Ecuador, no es menos cierto que forma parte de la historia y no merece ser invisibilizada. Recientemente, una nueva generación de investigadores ha captado interés por el tema y ha conducido nuevas investigaciones (Cussen, 2006; Arre Marfull y Barrenechea, 2017), así como un nuevo reconocimiento por parte del Estado de Chile. En 2013, el INE (Instituto Nacional de Estadísticas) llevó a cabo por primera vez una encuesta de caracterización de la población afrodescendiente de la región de Arica y $\mathrm{Pa}$ rinacota, y los resultados mostraron que un 4,7\% de los encuestados se consideran afrodescendiente. Hasta la fecha, esta encuesta no ha sido replicada en otras regiones del país. Por otra parte, en 2018 el Senado chileno aprobó la idea de legislar el reconocimiento constitucional al pueblo afrodescendiente.

La llegada de población africana a Sudamérica producto de la esclavitud fue dispar: se calcula que entre los años 1551 y 1850 llegaron al menos 3,5 millones de esclavos africanos por puertos brasileños (Alves-Silva et al., 2000). En las colonias españolas el influjo fue menor dada la figura de la encomienda, que proveía de trabajo esclavo usando población nativa (Cussen, 2006).

\section{Migración en tiempos recientes}

Uno de los resultados obtenidos es la alta proporción de linajes amerindios sureños, lo que revela la importante influencia de la migración sur-norte en la conformación de las poblaciones actuales de la región de Antofagasta. Dos procesos de desarrollo económico podrían dar cuenta de estos resultados: el desarrollo de la industria salitrera y la gran minería del cobre. La industria salitrera floreció luego que Tarapacá y Antofagasta fueran anexadas como consecuencia de la Guerra del Pacífico (1879-1883), obteniendo Chile el monopolio mundial de la exportación de salitre. El crecimiento de la región fue explosivo, aumentando de 21.213 a 113.323 habitantes en el plazo de 20 años, como se observa en la Figura 3 (Reyes-Madrid, 2019), y cuadruplicando la tasa de migración respecto al promedio chileno (19,5\% versus 4,2\%; González, 2011).

El auge del salitre, sin embargo, duró poco. Las exportaciones de este mineral cayeron por sobre un $90 \%$ con posterioridad a la invención del salitre sintético y la depresión de los años treinta, convirtiendo a las salitreras en pueblos fantasmas cuyo único destino hoy en día es turístico. A pesar de encontrarse deshabitadas en la actualidad, 24 participantes agenciaron el lugar de nacimiento de la abuela materna o la madre en algunas de las salitreras del norte de Chile (oficinas María Elena, Pedro de Valdivia, Victoria, Anita, Pampa Unión, Agua Santa, Potrerillos, Humberstone, Catalina, Baquedano y Chacabuco). Los datos de esta muestra son interesantes, puesto que los porcentajes de los linajes sureños son bajos respecto a los de las ciudades costeras: $\mathrm{B} 2 \mathrm{i} 2=$ $4,5 \%, \mathrm{C} 1 \mathrm{~b} 13=4,5 \%$ y D1g $=13,6 \%$, lo que suma $22,7 \%$ del total de los linajes, versus el $36,8 \%$ en la

Respecto de Chile, los registros muestran que desde el comienzo de la colonización hubo un flujo continuo de esclavos africanos, aunque en números pequeños. Según el censo del obispado de Santiago de 1777-1778, entre $1 \%$ y $4 \%$ de la población total correspondía a población africana, y Coquimbo, Santiago y Colchagua los lugares donde se concentraban (Klein y Carmagnani, 1965). Lamentablemente, la falta de interés de los colonos por conocer los orígenes de los esclavos que adquirían ha repercutido en que hoy no se cuente con registro de lugares de nacimiento, nombres o apellidos, dificultando el rastreo de los linajes africanos (Cussen, 2016). 


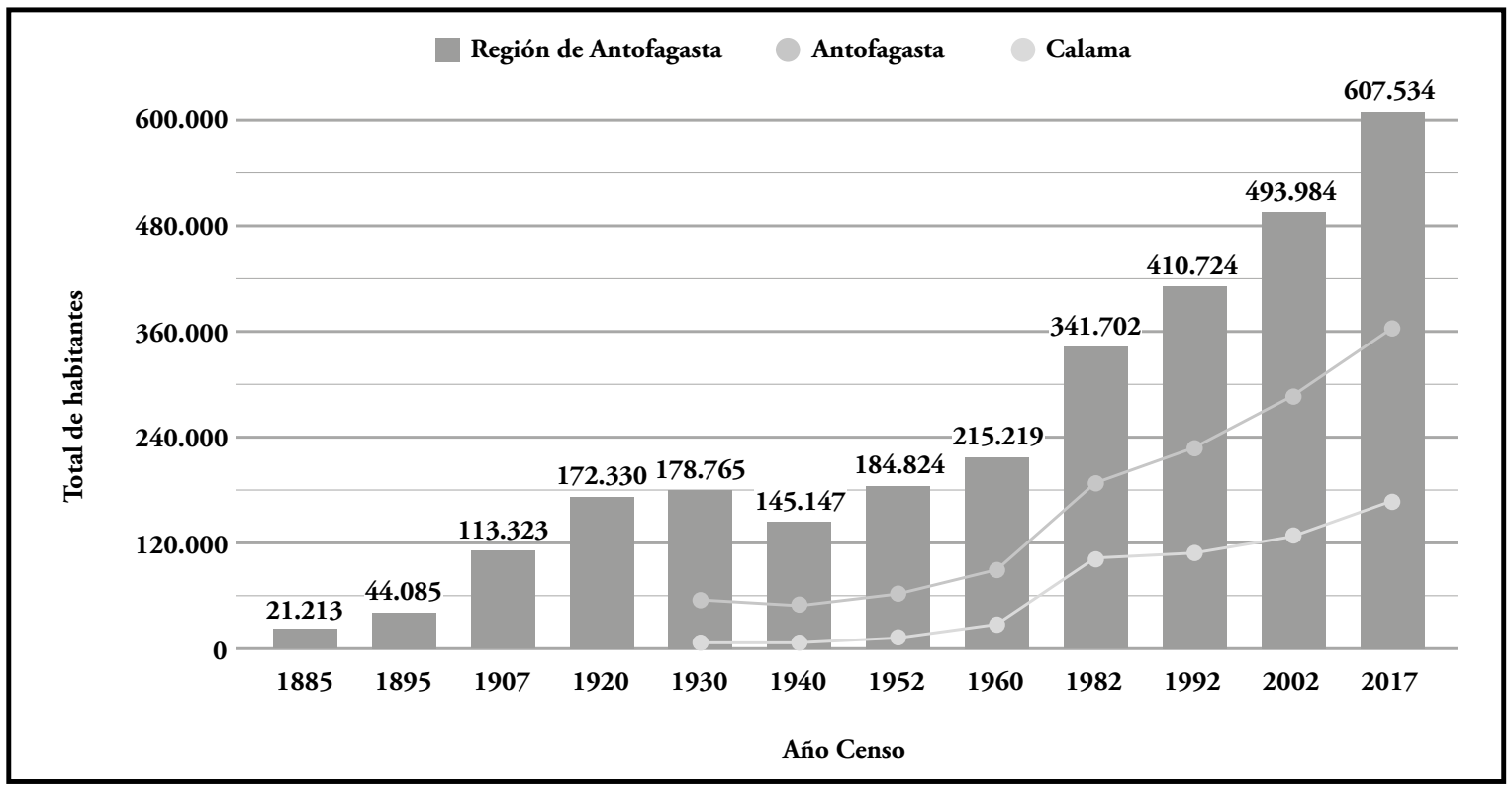

Figura 3. Crecimiento demográfico de la región de Antofagasta entre los años 1885-2017. Gráfico combinado que presenta el total de habitantes para los territorios de la actual segunda región (barras) y las ciudades de Antofagasta y Calama desde el ańo 1930 (líneas superior e inferior respectivamente). Obtenido de Reyes-Madrid (2019).

costa. Particularmente interesante es el linaje B2i2, presente en la costa en un $17,2 \%$ y en Calama en un $17,5 \%$, el cual se encuentra fuertemente ligado a poblaciones indígenas del sur de Chile (De Saint Pierre et al., 2012). Estos resultados muestran que si bien el auge salitrero tuvo una influencia en la migración sur-norte, no fue el principal motor. El otro proceso que trajo desarrollo económico a la región fue la gran minería del cobre, especialmente con el comienzo de la producción del mineral en Chuquicamata a partir de 1915 (Marín, 1920). La explotación industrial de Chuquicamata trajo cambios a la región, y en especial a la zona de Calama, nunca antes vistos. De partida, próximo a la ciudad de Calama se desarrolló un campamento minero destinado a albergar a los trabajadores y sus familias. Según Gundermann (2004), numerosos habitantes de pueblos pequeños de la zona se especializaron en la minería y acabaron migrando a los centros urbanos, en especial hacia Calama y Chuquicamata. Los datos censales dan cuenta de esta situación; según el Censo 2002, del total de 9.658 atacameńos registrados, el 90,5\% de ellos habitaría en el área urbana de Calama (Imilan, 2007). Nuestros datos dan cuenta de esta realidad, ya que el $75 \%$ de individuos de nuestra muestra de Pueblos del interior nació en Calama, incluyendo seis de los ocho individuos portadores del linaje B2$455+\mathrm{T}$ asociado a atacameños (De Saint Pierre et al., 2012), además del 3,5\% de dicho linaje presente en la muestra Calama-Chuquicamata. Por contraste, otros linajes podrían dar cuenta de procesos diferentes. Los haplogrupos andinos B2aj, B2y y B2ai $(15,9 \%$ en total $)$ pueden en realidad estar reflejando la inmigración boliviana, la principal fuente de migrantes extranjeros en la región (González, 2008). El haplogrupo B2aj se encuentra en porcentajes entre el 30 y $70 \%$ en población boliviana, en especial aymara del lago Titicaca (Sandoval et al., 2013), demostrando la intensa conexión del altiplano boliviano con el chileno. Dado que la evidencia de conexión entre San Pedro de Atacama y la zona del lago Titicaca está documentada para tiempos prehispánicos (Berenguer y Dauelsberg, 1989; Kolata 1993; Llagostera, 1996), es difícil poder distinguir la temporalidad de la proveniencia del linaje B2aj presente tanto en la muestra de Pueblos del interior (25\%) como en la de Calama-Chuquicamata (9,5\%). Los haplogrupos D1g y B2i2 (con valores similares a los encontrados en la costa) están dando cuenta de que las migraciones provenientes del sur de principios de siglo XX tuvieron también una gran influencia a la hora de conformar la actual población de Calama. 
Tabla 3. Correspondencia entre lugar de nacimiento y lugar de muestreo de los individuos participantes, y de sus madres y abuelas maternas.

\begin{tabular}{|l|c|c|c|}
\hline \multicolumn{1}{|c|}{ Lugar de muestro } & $\begin{array}{c}\text { Lugar de nacimiento } \\
\text { participante }\end{array}$ & $\begin{array}{c}\text { Lugar de nacimiento } \\
\text { madre }\end{array}$ & $\begin{array}{c}\text { Lugar de nacimiento } \\
\text { abuela materna }\end{array}$ \\
\hline Pueblos del interior & $6 / 32(18,8 \%)$ & $23 / 32(71,9 \%)$ & $32 / 32(100 \%)$ \\
\hline $\begin{array}{l}\text { Antofagasta-Tocopilla- } \\
\text { Mejillones }\end{array}$ & $49 / 83(59 \%)$ & $60 / 83(72,3 \%)$ & $83 / 83(100 \%)$ \\
\hline Calama-Chuquicamata & $47 / 61(77 \%)$ & $45 / 61(73,8 \%)$ & $61 / 61(100 \%)$ \\
\hline
\end{tabular}

La recolección de datos de lugares de nacimiento de los participantes, y de sus padres/madres y abuelos/ as, nos permite adentrarnos en patrones migratorios y de movilidad de los últimos 70-80 ańos para la región de Antofagasta, al comparar los lugares de nacimiento de los participantes con los de la abuela materna. Como es de esperar, el patrón migratorio varía entre los grandes centros urbanos respecto de los pueblos pequeños (Tabla 3 ).

Mientras que la diferencia entre el lugar de nacimiento del participante y su abuela materna varía entre un $23 \%$ para Calama-Chuquicamata y un $41 \%$ en Costa norte, en la submuestra Pueblos del interior, esta diferencia aumenta a un $81,2 \%$. Este resultado puede explicarse principalmente por la importante migración desde los pueblos pequeños $y$ aislados a centros urbanos, proceso que ha sido documentado para diferentes regiones de Chile (Gundermann y González, 2008; Carrasco y González, 2014; Valdés y Rebolledo, 2015), y dentro de ellos la zona de San Pedro de Atacama (Imilan, 2007). Si bien la movilidad poblacional en Atacama dentro del altiplano está muy bien documentada y no es un proceso reciente, en esta muestra el proceso migratorio "campo-ciudad" se observa como un proceso acentuado en los últimos 50 años. Esta diferencia puede deberse a que la conectividad de San Pedro de Atacama con Calama es relativamente reciente. La carretera que conecta con San Pedro, Ruta 23-CH, fue inaugurada en 1967; anterior a eso, el trayecto entre ambas localidades tomaba varias horas, entre terreno de altura y dificultoso, por lo que no es de extrańar que la apertura de este nuevo camino trajera grandes cambios a los pueblos de los valles y tuviera consecuencia directa en el aumento de migración de los habitantes de San Pedro a los centros urbanos.

\section{Conclusiones}

En este estudio a través del análisis de 16 haplogrupos y subhaplogrupos mitocondriales en una muestra de la población actual de la costa y los valles interiores de la región de Antofagasta, pudimos evidenciar diferentes situaciones que dan cuenta de dinámicas particulares.

Por una parte, la composición particular de linajes andinos en el área, con su ausencia en la costa y una presencia importante $(50 \%)$ en la población de pueblos pequeños nos revela aislamiento entre ambas poblaciones, lo cual pudo ser correlacionado con evidencia etnográfica y arqueológica. Por otra parte el alto porcentaje de los linajes sureños D1g, B2i2 y C1b13 en la Costa y Calama, junto a una ausencia total en la muestra Pueblos del interior, nos permite, además de corroborar lo anterior, evidenciar la importancia de la migración de población proveniente del sur hacia los centros urbanos. Una comparación entre las muestras de Calama-Chuquicamata y oficinas salitreras apunta al desarrollo minero, el cual no solo tuvo efectos en promover la migración, sino que transformó profundamente la realidad de la población del área de San Pedro impulsando grandes cambios, principalmente en lo relacionado a la migración "campo-ciudad".

No obstante lo anterior, es importante tener en cuenta las limitantes del marcador utilizado, el cual es transmitido por vía materna, reflejando solo el 
linaje femenino de la población. Dada la posibilidad de patrones de migración diferencial entre mujeres y hombres, no es posible descartar que la historia poblacional entregada con un marcador de herencia masculino, como cromosoma $\mathrm{Y}$, pueda contener algunas diferencias respecto de lo mostrado con el ADN mitocondrial. La utilización de marcadores de ancestría nucleares, incluyendo cromosoma $Y$, son entonces necesarios para confirmar los patrones aquí revelados.

\section{Agradecimientos}

Agradecemos a todos los donadores de ADN, de las ciudades de Antofagasta y Calama, que gentilmente aceptaron participar en este proyecto. Agradecemos además a Margarita Reyes, Andrea Eyquem, Fernanda Herrera y Paloma Contreras por su colaboración en la toma de muestra. A Sandra Flores, por su coordinación del terreno y laboratorio. Agradecemos también a los dos revisores anónimos y editores de la revista, quienes con sus comentarios y sugerencias nos ayudaron a mejorar este artículo. Esta investigación se realizó con el financiamiento del proyecto FONDECYT de iniciación en investigación 11150453, "Análisis y descripción de mitogenomas, haplogrupos mitocondriales y de cromosoma $\mathrm{Y}$ amerindios en el norte de Chile, comuna de San Pedro de Atacama”.

\section{Referencias citadas}

Alves-Silva, J., Da Silva Santos, M., Guimarães, P. E., Ferreira, A. C., Bandelt, H. J., Pena, S. D., y Prado, V. F. (2000). The ancestry of Brazilian mtDNA lineages. The American Journal of Human Genetics, 67, 444-461. DOI:10.1086/303004.

Arre Marfull, M. y Barrenechea, P. (2017). De la negación a la diversificación: los intra y extra muros de los estudios afrochilenos. Tabula Rasa, 27, 129-160. DOI:10.25058/20112742.447.

Ballester, B. R. y Gallardo, F. (2017). La versatilidad del parentesco en la reproducción social: El caso de los cazadores-pescadores marinos del desierto de Atacama (siglos XVI-XIX, norte de Chile). Boletín de la Sociedad Chilena de Arqueología, 47, 1-22.
Berenguer, J. y Dauelsberg, P. (1989). El Norte Grande en La Órbita de Tiwanaku. En Hidalgo, J., Schiapacasse, V., Aldunate, C. y Solimano, I. (Eds). Culturas de Chile. Prehistoria desde sus origenes hasta los albores de la Conquista (pp. 128-150). Santiago: Editorial Andrés Bello.

Bibar, J. de (1966 [1558]). Crónica y Relación Copiosa y Verdadera de los Reinos de Chile. Santiago: Fondo Histórico y Bibliográfico José Toribio Medina.

Carrasco, A. M. y González, H. (2014). Movilidad poblacional y procesos de articulación rural-urbano entre los Aymara del norte de Chile. Si Somos Americanos. Revista de Estudios Transfronterizos, 24, 217-231. DOI:10.4067/ S0719-09482014000200009.

Castro, V. (2001). Atacama en el tiempo. Territorios, identidades, lenguas. (Provincia El Loa, II Región). Anales de la Universidad de Chile, 13. DOI:10.5354/07178883.2010.2527

Castro, V., Berenguer, J., Gallardo, F., Llagostera, A., y Salazar, D. (2016). Vertiente Occidental Circumpuneña. Desde las Sociedades Posarcaicas hasta las Preincas (ca. 1500 años aC a 1470 años dC). En Falabella, F., Uribe, M., Sanhueza, L., Aldunate, C. e Hidalgo, J. (Eds.). Prehistoria en Chile, desde sus primeros habitantes hasta los Incas (pp. 239-283). Santiago: Editorial Universitaria.

Cussen, C. (2006). El paso de los negros por la historia de Chile. Cuadernos de Historia, 25, 45-48.

Cussen, C. (2016). Relato histórico de la formación del actual pueblo chileno. En Berríos, S. (Ed.). El ADN de los chilenos y sus orígenes genéticos (pp. 17-34). Santiago: Editorial Universitaria.

De Saint Pierre, M., Bravi, C. M., Motti, J. M., Fuku, N., Tanaka, M., Llop, E., Bonatto, S. L. y Moraga, M. (2012). An alternative model for the early peopling of southern South America revealed by analyses of three mitochondrial DNA haplogroups. PLoS One, 7, e43486. DOI:10.1371/journal.pone.0043486.

Echeverri, M. M. (2016). Otredad racializada en la migración forzada de afrocolombianos a Antofagasta. Nomadas, 45, 91-104. DOI:10.30578/nomadas.n45a6

Excoffier, L. y Lischer, H. E. L. (2010). Arlequin suite ver 3.5: A new series of programs to perform population 
genetics analyses under Linux and Windows. Molecular Ecology Resources, 10, 564-567. DOI:10.1111/j.17550998.2010.02847.x.

Eyheramendy, S., Martinez, F. I., Manevy, F., Vial, C., y Repetto, G. M. (2015). Genetic structure characterization of Chileans reflects historical immigration patterns. Nature Communications, 6, 64-72. DOI:10.1038/ ncomms 7472 .

Fuentes, M., Pulgar, I., Gallo, C., Bortolini, M. C., Canizales-Quinteros, S., Bedoya, G., González-José, R., Ruiz-Linares, A. y Rothhammer, F. (2014). Gene geography of Chile: regional distribution of American, European and African genetic contributions. Revista Médica de Chile, 142, 281-289. DOI:10.4067/S003498872014000300001.

Gómez-Carballa, A., Moreno, F., Álvarez-Iglesias, V., Martinón-Torres, F., García-Magariños, M., Pantoja-Astudillo, J. A., Aguirre-Morales, E., Bustos, P. y Salas, A. (2016). Revealing latitudinal patterns of mitochondrial DNA diversity in Chileans. Forensic Science International. Genetics, 20, 81-88. DOI:10.1016/j.fsigen.2015.10.002.

Gómez-Carballa, A., Pardo-Seco, J., Brandini, S., Achilli, A., Perego, U. A., Coble, M. D., Diegoli, T. M., ÁlvarezIglesias, V., Martinón-Torres, F., Olivieri, A., Torroni, A. y Salas A. (2018). The peopling of South America and the trans-Andean gene flow of the first settlers. Genome Research, 28, 767-779. DOI:10.1101/gr.234674.118.

González, J. (2008). La emigración boliviana en la precordillera de la región de Antofagasta, 1910-1930. Redes sociales y estudios de casos. Revista de Ciencias Sociales (Cl), 21, 65-81.

González, J. (2011). Notas sobre la inmigración argentina en la precordillera antofagastina durante el ciclo salitrero. Estudios Atacameños. Arqueología y Antropologia Surandinas 42, 189-204. DOI:10.4067/S071810432011000200010.

Grebe, M. E. e Hidalgo, B. (1988). Simbolismo Atacameño: un aporte etnológico a la comprensión de significados culturales. Revista Chilena de Antropologia, 7, 75-97, DOI:10.5354/0719-1472.2011.17614.

Gundermann, H. (2004). Inicios de siglo en San Pedro de Atacama: procesos, actores e imaginarios en una localidad andina. Chungara. Revista de Antropología Chilena, 36, 221-239. DOI:10.4067/S0717-73562004000100007.

Gundermann, H. y González, H. (2008). Pautas de integración regional, migración, movilidad y redes sociales en los pueblos Indígenas de Chile. Universum (Talca), 23(1), 82-115. DOI:10.4067/S0718-23762008000100006.

Hidalgo, J. (2004). Historia andina en Chile. Santiago: Editorial Universitaria.

Imilan, W. A. (2007). Socaireños en movimiento. Atacameños y Calama. Estudios Atacameños. Arqueología y Antropología Surandinas, 33, 105-123. DOI:10.4067/ S0718-10432007000100007.

INE (Instituto Nacional de Estadísticas) (2017). Segunda entrega de resultados definitivos Censo 2017.

Klein, H. y Carmagnani, M. (1965). Demografía histórica: la población del obispado de Santiago, 1777-1778. Boletín de la Academia Chilena de Historia, XXXII (72), 57-74.

Knudson, K. J., Pestle, W. J., Torres-Rouff, C. y Pimentel G. (2010). Assessing the life history of an andean traveller through biogeochemistry: Stable and radiogenic isotope analyses of archaeological human remains from Northern Chile. International Journal of Osteoarchaeology, 22, 435-451. DOI:10.1002/oa.1217.

Kolata, A. (1993). The Tiwanaku. Portrait of an Andean Civilization. Cambridge: Blackwell.

Kumar, S., Stecher, G., y Tamura, K. (2016). MEGA7: Molecular Evolutionary Genetics Analysis version 7.0 for bigger datasets. Molecular Biology and Evolution, 33, 1870-1874. DOI:10.1093/molbev/msw054.

Lambert, B. (1977). Bilaterality in the Andes. En Bolton, R. y Meyer, E. (Eds.). Andean kinship and marriage (pp. 1-27). Washington D.C.: American Anthropological Association.

Latcham R. (1910). ¿Quiénes eran los changos? Anales de la Universidad de Chile, 126, 377-439, DOI:10.5354/07178883.2012.25100.

Llagostera, A. (1996). San Pedro de Atacama: Nodo de complementariedad reticular: En la integración surandina cinco siglos después. Estudios y Debates Regionales Andinos, 91, 17-42. 
Llamas, B., Fehren-Schmitz, L., Valverde, G., Soubrier, J., Mallick, S., Rohland, N.,... y Haak W. (2016). Ancient mitochondrial DNA provides high-resolution time scale of the peopling of the Americas. Science advances, 2, e1501385. DOI:10.1126/sciadv.1501385.

Lott, M. T., Leipzig, J. N., Derbeneva, O., Xie, H. M., Chalkia, D., Sarmady, M., Procaccio, V. y Wallace, D. C. (2013). mtDNA variation and analysis using MITOMAP and MITOMASTER. Current Protocols in Bioinformatics, 1, 1-26. URL: http://www.mitomap.org, DOI:10.1002/0471250953.bi0123s44.

Lozano Machuca, J. (1885 [1581]). Carta del Factor de Potosí al virrey del Perú, en donde se describe la Provincia de los lipes. Relaciones Geográficas de Indias, Perú, T. II, Apéndice III. Madrid: Ministerio de Fomento.

Marín, S. (1920). La industria del cobre en Chile. Santiago: Imprenta Universitaria.

Martínez, J. L. (2005). Imágenes y soportes andinos coloniales. Notas preliminares. Revista Chilena de Antropologia Visual, 5, 113-132.

Mayer, E. y Alberti, G. (1974). Reciprocidad andina ayer y hoy, en reciprocidad e intercambio en los Andes peruanos. Lima: Instituto de Estudios Peruanos.

Mideplan (2004). Caracterización de la Población: Región de Antofagasta. División de Planificación Regional, Departamento de Competitividad Regional, Ministerio de Planificación y Cooperación, Gobierno de Chile, pp. 9-12.

Moraga, M. L., Rocco, P., Miquel J. F., Nervi, F., Llop, E., Chakraborty, R., Rothhammer, F. y Carvallo, P. (2000). Mitochondrial DNA polymorphisms in Chilean aboriginal populations: implications for the peopling of the southern cone of the continent. American Journal of Physical Anthropology, 113, 19-29. DOI:10.1002/10968644(200009)113:1<19::AID-AJPA3>3.0.CO;2-X.

Moraga, M. L., Pezo, P., De Saint Pierre, M. (2016). Una mirada a las poblaciones fundadoras mediante el estudio de marcadores genéticos de herencia uniparental. En Berríos, S. (Ed.). el ADN de los chilenos y sus orígenes genéticos (pp. 62-87). Santiago: Editorial Universitaria.

Morales, H. (1997). Pastores trashumantes al fin del mundo. Un enfoque cultural de la tecnologí: en una comunidad andina de pastores (Memoria de pregrado Antropología Social), Universidad de Chile, Santiago, Chile.

Morales, H. (2013). Construcción social de la etnicidad. Ego y alter en Atacama. Estudios Atacameños. Arqueología y Antropología Surandinas, 46, 145-164. DOI:10.4067/ S0718-10432013000200009.

Morales, H. (2018). Habitar el Desierto. Cuadernos de Campo de la Puna Atacameña (1995-2015). Colección de Etnografía. Servicio Nacional del Patrimonio Cultural. Subdirección de Investigación. Santiago, Chile.

Murra, J. (1972). El control vertical de un máximo de pisos ecológicos en la economía de las sociedades andinas. En Murra, J. V. (Ed.). Visita de la provincia de León de Huánuco en 1562 por Ínigo Ortiz de Zúñiga, vol. 2 (pp. 427-468). Universidad Nacional Hermilio Valdizán, Huánuco, Perú.

Murra, J. (1975). Formaciones económicas y políticas del mundo andino. Lima: Ed. Instituto de Estudios Peruanos.

Núñez, L., Cartajena, I., Carrasco, C., De Souza, P., y Grosjean, M. (2006). Emergencia de comunidades pastoralistas formativas en el sureste de la Puna de Atacama. Estudios Atacameños. Arqueología y Antropología Surandinas, 32, 93-118. DOI:10.4067/S071810432006000200008.

Núñez, L. y Dillehay, T. (1979). Movilidad Giratoria, Armonía Social y Desarrollo en los Andes Meridionales: Patrones de Tráfico e Interacción Económica. Universidad de Norte, Antofagasta, Chile.

Núñez, L. y Briones L. (2017). Tráfico e interacción entre el oasis de Pica y la costa arreica en el desierto Tarapaqueño (norte de Chile). Estudios Atacameños. Arqueología y Antropologia Surandinas, 56, 133-161. DOI:10.4067/S071810432017000300006.

Oviedo y Valdés, G. (1855 [1547]) Historia General Natural de las Indias, Islas y tierra Firme del Mar. Madrid: Océano Imprenta de la Real Academia de la Historia.

Philippi, R. (1860). Viaje al Desierto de Atacama hecho de orden del Gobierno de Chile en el verano 1853-1854. Halle, Sajonia: Librería Eduardo Antón.

Quinque, D., Kittler, R., Kayser, M., Stoneking, M. y Nasidze, I. (2006). Evaluation of saliva as a source of 
human DNA for population and association studies. Analytical Biochemistry, 353, 272-277. DOI:10.1016/j. ab.2006.03.021.

Reyes-Madrid, M. (2019). Composición genética de la Región de Antofagasta: Un estudio a partir del Cromosoma Y. (Memoria de pregrado Antropología Física), Universidad de Chile, Santiago, Chile, p. 18.

Salas, A. M. (1945). El Antigal de Ciénega Grande (Quebrada de Purmamarca, Provincia de Jujuy). Buenos Aires: Universidad de Buenos Aires, Publicaciones del Museo Etnográfico de la FFyL, Imprenta de la Universidad.

Sandoval, J. R., Lacerda, D. R., Jota, M. S., Salazar-Granara, A., Vieira, P. P. R., Acosta, O., Cuellar, C., Revollo, S., Fujita, R., Santos, F. R. y Genographic Project Consortium (2013). The genetic history of indigenous populations of the Peruvian and Bolivian Altiplano: the legacy of the Uros. PLoS One, 8, e73006. DOI:10.1371/ journal.pone.0073006.

Sanhueza, C. (1992). Tráfico caravanero y arriería colonial en el siglo XVI. Estudios Atacameños, 10, 173-187. DOI:10.22199/S07181043.1992.0010.00016.
Santoro, C. M., Capriles, J., Gayó, E. M., De Porras, M., Maldonado, A. G., Standen, V.,... Marquet, P. (2016). Continuities and discontinuities in the socio-environmental systems of the Atacama Desert during the last 13,000 years. Journal of Anthropological Archaeology, 46, 28-39. DOI:10.1016/j.jaa.2016.08.006.

Sendón, P. (2016). Bilateralidad, agnación y matrifocalidad entre los pastores del sur peruano: una lectura censal y genealógica (siglos XIX-XX). Indiana, 33, 31-58. DOI:10.18441/ind.v33i2.31-58.

Serrano, A. (1947). Los aborigenes argentinos. Buenos Aires: Editorial Nova.

Valdés, X. y Rebolledo, L. (2015). Géneros, generaciones y lugares: cambios en el medio rural de Chile Central. Polis, Revista Latinoamericana, 14, 491-513.

Van Oven, M. y Kayser, M. (2009). Updated comprehensive phylogenetic tree of global human mitochondrial DNA variation. Human Mutation, 30, E386-E394. www.phylotree.org. DOI:10.1002/humu.20921. 